\title{
TOWARDS “TOURISM FOR ALL” - IMPROVING MAPS FOR PERSONS WITH REDUCED MOBILITY
}

\author{
J. Nowak Da Costa ${ }^{1, *}$, C. Bielski ${ }^{2}$ \\ ${ }^{1}$ Faculty of Civil Engineering and Geodesy, Military University of Technology, Warsaw, Poland - joanna.nowakdc@wat.edu.pl \\ ${ }^{2}$ EOXPLORE UG (haftungsbeschränkt), Weil am Rhein, Germany
}

Commission IV, WG IV/9

KEY WORDS: accessibility mapping, reduced mobility, disabled tourists, geovisualisation

\begin{abstract}
:
Standards and legislation are already in place to provide the necessary building requirements to improve mobility access for everyone. However, these requirements are not always adhered to for a variety of reasons even in cases of new constructions. Moreover, already existing structures and/or historical buildings built prior to such mobility requirements were put into force must be retrofitted. Consequently, a significant number of potential interesting locations are not accessible to persons with reduced mobility. For this reason, the focus of our research is on the expected content and availability of detailed mobility related information and how to improve the communication of accessibility information to users in order to evaluate the accessibility potential of public places and spaces to help persons with reduced mobility plan their outings by taking advantage of smart data and people in cities.
\end{abstract}

\section{INTRODUCTION}

There is a significant drive today within the context of Smart Cities to improve travel within a city and facilitate planning visits to places of interest and access to commercial centres. However, even with vast amounts of digital geographic and 3D data available today in some of the most connected cities of the world, stories are published demonstrating where mobility and transportation in the context of smart cities have failed. Two recent reports deal with re-routing of traffic in Los Angeles, USA (Ffrench, 2018) and access by mobility impaired individuals to a newly renovated shopping centre in Oxford, UK (Farivar, 2018).

According to Eurostat (Eurostat, 2015), more than 70\% of Europeans already live in cities and urban agglomerations and it is expected that worldwide, cities will house two-thirds of all people by 2050 . It is therefore imperative that we work to make cities liveable, safe, resilient, accessible, and adaptable to maintain citizens' wellbeing. This paper looks at the issue of map data acess and presentation through geovisualization or maps devoted to people with reduced mobility in urban areas who want to visit places of cultural significance. At this time, there is a need for better mobility related geospatial data and with the help of volunteered information, in the context of Smart Cities, this urban issue can be solved. The ultimate goal is to provide purpose driven mobility information so that anyone can plan their perfect day out no matter their transportation requirements. This can only be done through the collection of pertinent data and the involvement of those individuals that may not always have access to the most upto-date technologies and take advantage of smart city data and services.

\subsection{Diversity in the Target Group}

The United Nations Convention on the rights of persons with disabilities (UNCRDP, 2006) adopts a social model of disability (Oliver, 2013) and recognises that disability results from the

\footnotetext{
${ }^{*}$ Corresponding author
}

interaction between persons with impairments and attitudinal and environmental barriers that hinders their full and effective participation in society on an equal basis with others. Sharing Blichfeldt and Nicolaisens view (Blichfeldt and Nicolaisen, 2011), we are far from assuming that the obstacles, barriers and constraints which face disabled people are identical across all people with a disability.

For our study, the target group (TG) were persons whose reduced mobility requires them to use walking aids such as a wheelchair, walking stick, stroller, or even another persons arm for support. This includes the physically disabled, the elderly and families with very small children having to use pushchairs/strollers. Persons with reduced mobility or PRM is used in this paper and was taken from the European Network for Accessible Tourism (ENAT) (Laura, 2017).

The TG definition includes permanent and temporary constraints, such as a broken leg, and it should be underlined that a carer traveling with a small child or with a child in a pram; pregnant women or people of very short stature including children and seniors should be considered as PRM's (Darcy and Dickson, 2009). This interpretation is in-line with the definitions provided by the European Commission Regulation in the context of accessibility of the Union's rail system or those people's rights when traveling by air (EC Regulation No 1300/2014, EC Regulation No $1107 / 2006$ of the European Parliament and of the Council). Another limited mobility TG in many countries includes obese people as well as people of very large stature. The great diversity in mobility levels of the chosen TG is further characterized by a diversity in age, cognition and learning capabilities, and includes a diversity in technological experiences and aptitudes. People with multiple disabilities, such as vision impairment, are considered at this time out of scope for this article.

\subsection{Problems Facing the Target Group}

PRM are affected by architectural barriers that impede a person's freedom of movement (Laura, 2017) in public spaces such as 
buildings, on the street, and public transport. Steps, narrow doorways, or cracked sidewalks are only some of the architectural barriers people with walking impairments or wheelchairs encounter when navigating urban and/or semi-natural areas. Physical barriers can become a significant challenge and isolate PRM from the outside world. This potentially could have further physical and psychological effects and even lead to exclusion from society in general. Tracking using sensors and networking through social media of daily potential activities can help improve the overall situation of PRM because services can be put into place to provide some minimum level of assistance.

\section{INFORMATION IS KEY}

Few cities, tourist areas or cultural sites can boast accessibility for all but currently access to many facilities may be sufficient for some PRM to go ahead with tourist visits and activities. Unfortunately, the online survey and the consultation with national disability organisations in Europe revealed the lack of detailed information on accessibility (EC, 2015).

The importance of providing reliable and timely data on accessibility conditions at the destination is underlined by the World Tourism Organization (Organization, 2016a, Organization, 2016b). For this reason, the focus of our research is on the availability and communication efficiency of detailed mobility related information in order to evaluate the accessibility potential of public places and spaces to help persons with reduced mobility plan their outings by taking advantage of smart data and people in cities.

\subsection{Accessibility Information Users' Requirements}

To determine some general user requirements based on PRM accessibility in Poland, existing literature was analysed (Kaganek et al., 2017, Błedowski et al., 2012). The cited references revealed the following:

1. Architectural barriers make it difficult for people with limited independence to move around the city;

2. Barriers related to access to medical services is perceived as a boundary condition that helps enable participation in urban life;

3. Financial barriers related to having insufficient financial resources.

Moreover, the perception of barriers to participation in tourism most often depended on the subjects degree of disability (Kaganek et al., 2017).

Twenty-two PRM living in two neighbouring blocks of flats were interviewed for this paper to collect user requirements. The interviewees were three wheelchair users (aged 24, 47 and 51), seven mothers (aged 21-47) with small children, and twelve older people (aged 60-75 years) that were mobile enough to practice tourism. They were living in residential buildings from the Communist era in the Eastern European Block in the western part of Warsaw.

The survey participants were asked what accessibility related information they required and at what point during the planning phase or visit.The test location was a visit to the Palace and Park in Wilanów, a historical site found in the south-eastern part of the city and a different district of Warsaw from where the participants lived. The site was deliberately chosen because it a well-known tourist destination, an official National Historic Monument and the former summer residence of King Jan III Sobieski. The main conclusion from talking to the above mentioned test cases with mobility issues is the fact that they feel excluded from normal life. Essentially, they are afraid of impassable routes and other architectural barriers or the unavailability of accessible public toilets. Such issues made them feel like they were imprisoned at home and the interviewees underlined that they need to understand the entire journey before considering the potential possibility of visiting a tourist attraction or making vacation related decisions. While on site, the focus should be on sightseeing and enjoyment and not on searching for a route and/or changing one's destination because the path taken was impassable.

\subsection{Accessibility Information Availability}

To verify the findings concerning the lack of availability, the difficulty to understand and the reliability of accessibility information, 30 tourist and historic web sites, of which two thirds were located in Poland, were searched. This revealed that targeted information on accessibility is generally provided. Moreover, this information was provided both in the local language and in English. The English version however, when the web sites originated from non-English speaking counties, was often limited and less detailed. This occurred in $35 \%$ of cases. The most striking differences in providing disabled access information between the different websites were the entry points to find the accessibility information and the levels of detail. The entry points were not intuitive and/or standardised. For example, some provided the links to the wanted information on the home page and/or main menu providing a direct entry point. Other websites provided this link indirectly such as through a subpage menu or a hyperlinked phrase within a text. Others provided no link and the accessibility information was only found by using the site's search engine.

The following provides examples of two different levels of detail. The first museum ${ }^{1}$ provides little detail and only the following statement: The museum is partially accessible. The second museum $^{2}$ provides a much more appropriate level of detail: Persons with motor disabilities may also enter the Museum through the entrance from Anielewicza Street. There is a $25 \mathrm{~m}$ ramp with a $5 \%$ incline that leads to the entrance, made of granite cobble paving. The side entrance consists of revolving doors and a double door. The double doors do not open automatically, they are opened by security staff. However, in some cases there was so much text that it was difficult to absorb the information because the user was required to virtually read several pages that described in technical details each building entrance and mid-wall doors, etc.

We also found that the accessibility statements often referred to detailed site topography and using the proper names of buildings or other local points of interest. Such an example is the following $^{3}$ : There are wheelchair accessible public toilets in two locations in the gardens: close to the Amphitheater and near the Old Orangery. It is nearly meaningless for people who are not familiar with the environment, such as the case of tourists who have never been there, unless it is accompanied with an accessibility map or at least a map-like visualisation of the site.

\footnotetext{
${ }^{1}$ http://www.muzeumwp.pl/informacje.php

${ }^{2} \mathrm{http} / / /$ www.polin.pl/en/accessibility

${ }^{3}$ https://www.lazienki-krolewskie.pl/en/dostepnosc
} 
Among the sites researched, the following results can be summarised with respect to information on accessibility:

- In $63 \%$ of all cases the accessibility information was provided in text form only;

- In two cases (7\%), the textual information was accompanied by photographic documentation;

- While $30 \%$ of the visited websites provided some kind of map, mainly Google based in $23 \%$ of those cases or ESRI ArcGIS (server)-based in 7\%.

The reliability of the provided information on accessibility, its completeness and timely updating is sometimes suspect because in two cases the last website updates were made three or even up to ten years ago. It is also possible that in some cases accessibility details are not provided publicly because they are considered as sensitive information and therefore not provided via public websites. However, an alternative explanation is that for whatever reason, including budgetary constraints, such information is withheld because of cases where the public site is actually not accessible or has few accessible areas and/or facilities.

There are other challenges to actually providing accessibility options other than funding. For historical sites, the challenge is related to preserving the character of the historic and culturally significant property. For example, Buckingham Palace ${ }^{4}$ is a historic building where the floors may be uneven and visitors should take care. Another example is Wilanów ${ }^{5}$ where The installation of new facilities must take into account the unique character of the place and its historic dimension, we are therefore continuously working on solutions, which will satisfy the needs of our visitors on the one hand and the requirements faced by places of cultural and natural heritage on the other.

\section{CONVEYING ACCESSIBILITY INFORMATION}

The Article 9 of the Convention (UNCRDP, 2006) obliges taking appropriate measures to provide and promote various appropriate forms of assistance and support to enable and facilitate full participation in all aspects of life. They include both availability and transmission (communication) of accessibility information.

The task of conveying accessibility information especially as spatial information, could be more comprehensible if presented in graphic form because a graphic presentation completes the written word. The cartographic task is defined as transmitting (communicating) information to create knowledge (Brodersen, 2009, Brodersen, 2017, Slocum et al., 2009), whereby an accessibility map, accompanied by text (written or spoken), would make the process of communicating accessibility information more efficient. The entire concept of understanding a public site's accessibility is more comfortable and undemanding for the receiver of the information when viewed on a map.

\subsection{Participatory Sensing Approach}

Producing an accessibility map appears as an easy task because rules for thematic mapping are well established however, even the global spatial data provider Google Maps/Earth needed to postpone the provision of data for the disabled and only recently ${ }^{6}$ an-

\footnotetext{
${ }^{4}$ https://www.royalcollection.org.uk/visit/the-state-roomsbuckingham-palace/mobility-access\#/

${ }^{5}$ http://www.wilanow-palac.pl/accessibility.html

${ }^{6} \mathrm{https} / / / \mathrm{www}$. blog.google/products/maps/introducing-wheelchairaccessible-routes-transit-navigation/
}

nounced its availability (on March 15, 2018 the beta version was announced but the authors have not been able to test the functionality and/or information content). On the other hand, there is such a tremendous need for accessibility information that large numbers of volunteers are collecting and sharing them without any compensation (for details on the Volunteered Geographic Information (VGI) movement and data quality issues refer to (Goodchild, 2007, Nowak Da Costa, 2016) respectively). An example of a crowdsourcing website with user-generated content providing the information about accessibility including rating scales, photos and videos is wheelmap ${ }^{7}$. Another example of accessibility VGI is the Polish website Niepełnosprawnik ${ }^{8}$. It is a search engine that operates a digital database providing accessibility data to public facilities in the city of Warsaw as well as two other Polish cities. The service is provided by the TUS Foundation ${ }^{9}$, a Polish NGO that also trains many of the volunteers that collect the data through audits. The service provides very detailed text based accessibility information however, the geographic coverage is limited and is not updated frequently (approximately every 2-4 years). A subset of this information related to the Warsaw area are consumed regularly into the city of Warsaw open GIS $^{10}$.

The PRM living in or visiting the Polish capital can access the Warsaw Barrier Map (WBM) ${ }^{11}$ created by the SISKOM association. The creation and regular updating of this open and interactive web map of physical barriers for people with reduced mobility issues, especially barriers along main urban commuting routes, is the main tool of the Associations bottom-up action. The aim of this tool is to achieve wide recognition with respect to physical barriers and facilitating or accelerating their removal or update for both pedestrians and people with limited mobility.

Every year since 2014, the City of Warsaw cooperates with the SISKOM association and several other social organizations on the WMB project by reporting new physical barriers and updating the database together with volunteer mappers. This is further supported by allocating approximately PLN 1 million $(>200 \mathrm{~K}$ Euro) from the annual budget for project goals. The funds are intended for the improvement of approximately 70-140 small physical barriers hindering the everyday mobility of people with limited mobility such as high curbs at pedestrian crossings, lack of warning stripes, i.e. tactile paving for people with visual impairments, stairs or underpasses without appropriate ramps, uneven and/or narrow sidewalks, or obstacles in the road such as incorrectly placed road signs, benches, and even rubbish bins.

The WBM map limitation however, is that it only presents six types of barriers for PRM citizens. Physical barriers are represented as point objects that are mapped only along main city commuting routes. The Google Maps API is used with all its advantages such as regular automated updates and almost ubiquitous adoption as well as disadvantages such as the lack of built-in tools to display legends and limited options for map content personalization. The consequence is that the WBM map practically becomes a simple reference map instead of a dedicated accessibility thematic map. However, even with these issues, the WBM map continues to be a success.

\footnotetext{
${ }^{7}$ www.wheelmap.org

8 niepelnosprawnik.pl

${ }^{9} \mathrm{http}: / /$ www.tus.org.pl/en

${ }^{10} \mathrm{http}: / / \mathrm{www} \cdot \mathrm{mapa}$.um.warszawa.pl/mapaApp $1 / \mathrm{mapa}$ ?service=mapa

${ }^{11} \mathrm{http}$ ://mapabarier.siskom.waw.pl/warszawska-mapa-barier/
} 


\subsection{Map Design Practices for Visualising Accessibility}

For this article, desk research was performed that focused on the current designs of accessibility maps. As mentioned in section 2.2, there are few examples of dedicated maps directly related to the accessibility of historic, cultural sites and tourist attractions that describe the accessibility characteristics of public buildings or public outdoor spaces. The site surroundings of the destination, for example disabled access car parking places/spaces locations, are especially missing. Normally, a floor plan is made available that provides a unintuitive medium where a building's accessibility issues can be found. This type of visualisation is prevalently provided by museums with large exposition halls such as the Louvre in Paris ${ }^{12}$.

A non-exhaustive inventory of accessibility maps containing details relevant to mobility impaired users was scrutinized and the methods used to present the information examined. This was performed to see which solutions increased the efficiency of communicating the relevant map details. The overall impression of the displayed accessibility information was evaluated against the principles of map design presented in the field of cartography (Slocum et al., 2009, Brodersen, 2009, Dent et al., 2009, Field, 2018).

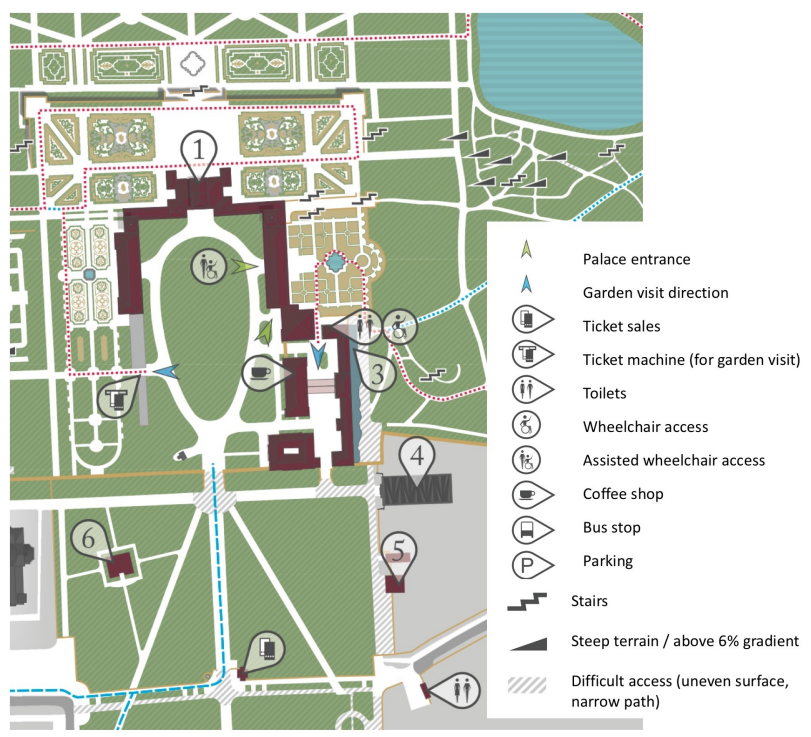

Figure 1. The Palace and Park in Wilanów map with legend, Warsaw, Poland

The accessibility map of the Palace and Park in Wilanów (Warsaw, Poland), presents both accessible, including conditionally accessible, features and architectural barriers while a high level of topographic detail, i.e. site inventory, data serves as the background reference data (Figure 1). The information complexity is in conflict with the simplicity map design principle and results in an ineffective map composition. It would be advisable to reduce the background topographic reference data complexity by excluding irrelevant components and to apply the data generalization and approximation. As an example the flower gardens are shown as detailed paths and the visualization does not contribute to the map aim of displaying access information. Their visualization by using their outer boundaries, a point symbol or even

\footnotetext{
${ }^{12} \mathrm{https} / / / \mathrm{www}$. louvre.fr/sites/default/files/medias /medias_fichiers/fichiers/pdf/louvre-plan-visitors-mobilityimpairments.pdf
}

omitting them would not constitute an information loss to the map reader searching for accessibility details at Wilanów. Moreover, the thematic information choice and visual resources application may lead to some confusion if used for on-site navigation. The theme of the map, i.e. access information, does not rise to the foreground unfortunately making the map difficult to read. The steep park paths or stairs located in the park are visualized using point cartographic symbols and therefore are not adjusted to the spatial nature of the objects. The map becomes so visually complex that it is not immediately apparent whether there are the routes allow free movement around the facility even though the map creators attempted to help the PRM by adding a suggested route to the museum that is unfortunately not barrier-free and a suggested tour of the gardens.

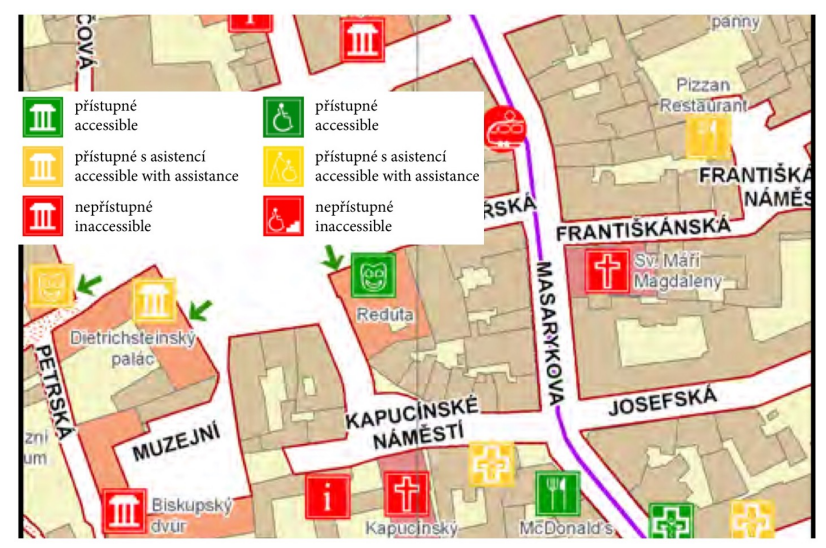

Figure 2. A map of accessibility of a region in the city of Brno, Czech Republic

An accessibility atlas for the city centre of Brno in the Czech Republic (Figure 2) is available free of charge at Brno City Municipality contact points. The map, prepared by the Masaryk University and Brno City Municipality in 2012, is a classical topographic map of the city enriched with thematic information of the degree of public buildings accessibility. This information is provided via cartographic point symbols and colours based on traffic light convention green-yellow-red (accessible, accessible with assistance, not accessible). Additionally, the same point symbols carry also the information about the type of map feature and therefore the location of the symbol relative to the described feature is important. Unfortunately, the Brno map reader often has doubts which topographic feature is related to a given symbol, thus the map content often do not match the needs of the user. Moreover, the choice of these associative but not sufficiently visible symbols that do not follow the principle of symbol distinguish-ability, further impede this information transmission.

The University of Kansas (USA) campus accessibility map (Figure 3 ) is an example of excellent resolving of foregroundbackground relationships, and efficient choice of the visual resources, i.e. using accessibility categories of hue, therefore their readers can easily sort out thematic (accessibility) information displayed on a map. The problem though, is the choice of the two point symbols representing ground level/ramp entrance and accessible entrance to limited sections of the building. They should contrast more strongly with each other since they represent features from different thematic subgroups.

Both, the Georgetown University and the Stockton University Campus accessibility maps (Figures 4 and 5, respectively) are 


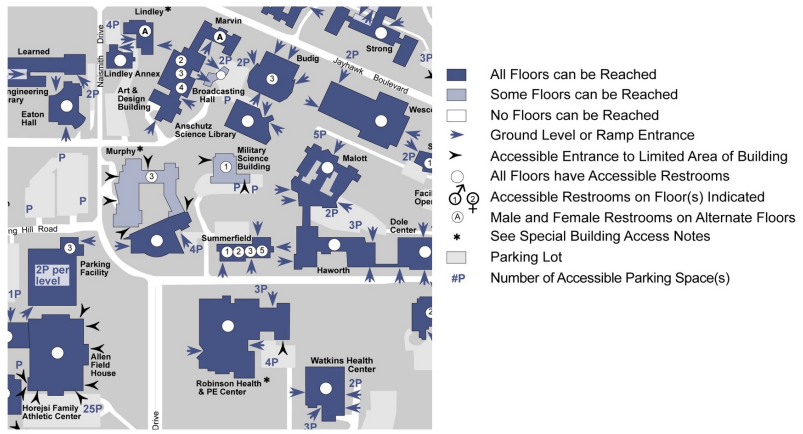

Figure 3. University of Kansas (USA) campus accessibility map.

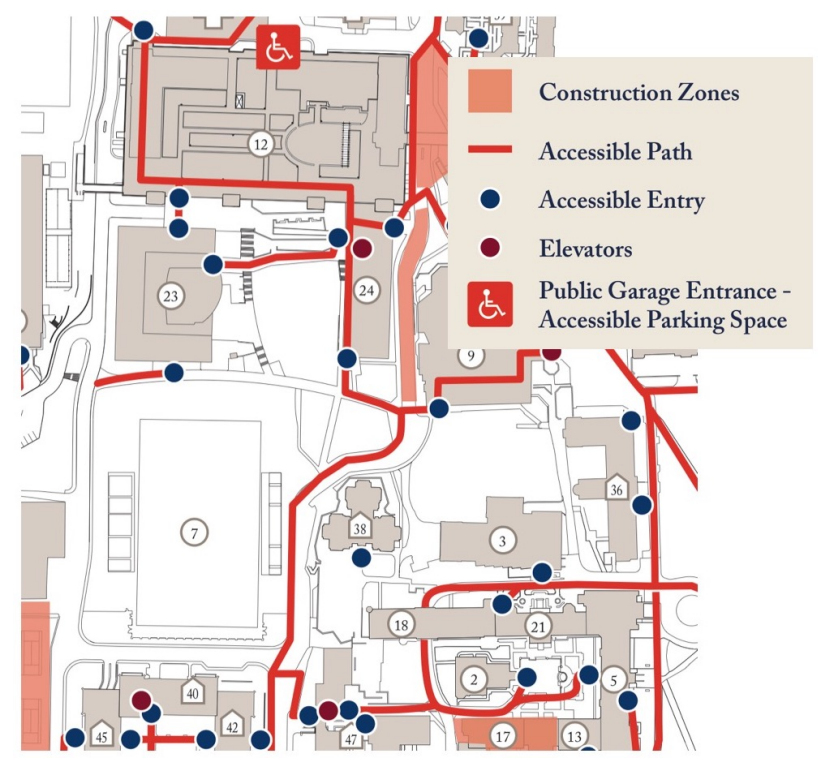

Figure 4. Georgetown University campus accessibility map.

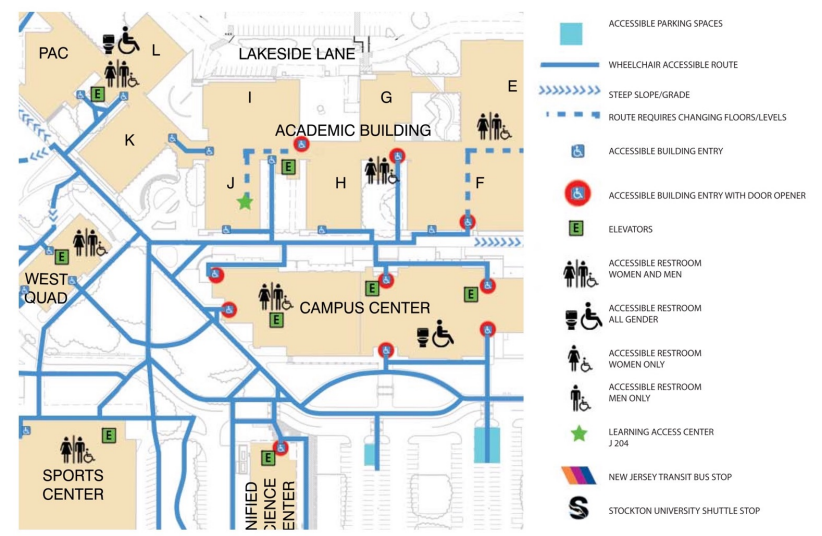

Figure 5. Stockton University (USA) campus accessibility map.

characterised by efficient figure-ground relationships resolving and map theme rising to the foreground. Moreover, these maps provide a PRM map reader with an aid of visualization of the barrier-free routes. The only potential issue is the choice of some symbols for visualisation. For example the Elevators symbol in figure 4 could contrast more strongly with the Accessible entry symbol, whereas the accessible building entry symbol in figure 5 could stand out more from the neighbouring wheelchair accessible route. The size of the accessible building entry symbol could be more adjusted to the rest of map symbols.

As shown by the limited examples above, there is a patchy approach regarding the production of accessibility information whether it relates to its content or graphic presentation and across different sectors. This demonstrates and reveals that accessibility is not always understood in the same way and it is often an addition to an available site map and sometimes seems to be an afterthought.

\section{UNIVERSAL ACCESSIBILITY MAPS}

Accessibility information has an associated location component and therefore should be considered as spatial or geographic information to be communicated graphically through geovisualisation.

\subsection{Effectively Communicating Accessibility Information}

The authors propose presenting accessibility information in a form of a thematic map that not only shows locations but also provides accessibility attributes and the relationships between places. A thematic map requires topographic information and therefore one can reuse existing topographic datasets highlighting only certain aspects of the topographic information that is important to achieve our goal. Other data categories on the map are perceived as the ground. Furthermore, depending on a sites area and complexity level, some minor topographic features will be generalized or omitted following the cartographic rule of reducing information complexity.

According to map design methods, first the map aim and purpose must be formulated and the target group defined. Second, the cartographers task is to establish what information should the map contain, how it should be organized, and what graphics to chose to maximise information understanding (Brodersen, 2001, Slocum et al., 2009). In the present context the map aim is to communicate accessibility information to the map reader by mapping both places and information. The map purpose is to provide the necessary and reliable accessibility information across the different stages of a PRM visitor's journey, including making travel choices with confidence or finding their accessible way to a destination with the help of the map. The map target users are the PRM together with their families and carers. The map information range is thematic information on accessibility and topographic information as background. The only issues left include how this information should be organized and what visual resources to choose to achieve our goal.

Although the visualization of the representation of spatial information on maps calls for data modelling, i.e. the process of discretizing spatial variation, approximation and generalization of real world geographic phenomenas (Goodchild, 1992), there is no new data modeling needed, providing the reuse of existing topographic datasets. Nevertheless, the structuring of thematic data is essential since classification is almost always a useful step toward understanding, even if the classes are extreme simplifications of the complexity actually present in the World or in our mental models of it (Mark, 1997).

\subsection{Classification of Accessibility Information}

A few well-defined classes positively influence the communication process because classes are easier to understand and thus 
help simplify and clarify the map message. Appropriate classification however, is not without challenges because the fewer classes that are established, the more legible the map but this comes at the expense of greater data generalization.

Inspired by the military cross-country movement maps, where three categories of traffic-ability are introduced: Go, Slow Go, No Go, regarding high, low, and no land traffic ability, respectively (Pimpa et al., 2014, Pokonieczny, 2016), we realised that accessibility data can also be perceived as ordinal data, i.e. ordered categorical data. Traditionally, mapping ordinal data cartographic methods are classed (medium to small-scale) choropleth map or a graduated symbol map in which the number of classes is equal to the number of data categories. The accessibility map proposed is a large-scale map presenting locations of various phenomena, similar to reference maps, and attributes of places and their relationships in the same manner thematic maps do. Consequently, we propose to use three classes: accessible, conditionally accessible where caution or assistance is needed, and not accessible. These categories apply both to buildings and path accessibility. The authors agree that there are no degrees of accessibility, i.e. if a facility does not conform to the accessibility guidelines, it is not accessible. However, the terms such as conditionally accessible or accessible with assistance are still in use. To the best of our knowledge, their intended meaning is that currently (or temporarily) only a part of a building (or other space or facility) is accessible. For example: 1. only background floor and first floor are accessible, 2. ramps are reasonable steep, i.e. having a slope of 6 to $10 \%$ (Space, 2011), 3. lift facilities are mobile and require booking assistance in advance.

\subsection{Accessibility Map Technology Related Issues}

With the expected data availability through both Smart Cities and Smart Citizens, it is expected that not only will accessibility information be more widely available but should also be improved on the fly as new validated information is uploaded to the cloud. Therefore, what technologies, methods or techniques should be used to encompass the diversity of the chosen TG? The following three items are proposed to provide targeted and reliable site accessibility information:

I Accessibility information must be visualised by the TG that has related text available. Cartographic visualisations able to adapt to user knowledge and comprehension should be possible as more details about location are provided from different sources;

II A purpose driven approach to map content that makes it possible to provide information specific to a PRM needs. The ability to make travel choices with confidence as well emphasize those thematic details of interest is paramount.

III Smartphones are becoming more ubiquitous and constantly adding new sensors that can help our TG based on their needs: visual, audio, sensory, and haptic feedback.

Many senior citizens strongly disapprove or cannot use smartphones (Müller et al., 2013) because of the technology barrier.They show skepticism about using technology in general due to age-related (e.g., cognitive decline) as well as technologyrelated (e.g., interface usability) barriers (Vaportzis et al., 2017) or simply the lack of resources (Kaganek et al., 2017) to purchase such devices. Therefore it is important to recognize the PRMs group diversity with regards their technological literacy and the introduction of a variety of map formats from non-interactive hard copy maps through to non-interactive soft copy maps (electronic versions) to those with GIS-type functionality - interactive geovisualisations. We propose interactive maps as a variant for TG members who are willing and capable to take advantage of them. An alternative for those unwilling or unable to use smartphones for map directions may be the development of simplified devices such as Internet of Things (IoT) that can be triggered in the vicinity of smartphones. One can imagine bluetooth enabled tourist site aids that are activated when communicating with a smartphone to provide accessibility information.

\subsection{Striving to make Public Spaces Accessible to Everyone}

As previously mentioned, having standards and legislation in place does not immediately translate into accessible mobility for everyone. Furthermore, many of these standards were developed years ago and did not take into consideration the technology available today or even the notion of Smart Cities. It is no surprise that the majority of the accessibility maps found were 'paper based', i.e. non-interactive and not easy to update. One can easily imagine PRM having an online mobility profile that can be linked with accessibility details of a public area to produce an appropriate on-demand map. However, to achieve this, Smart Cities must develop with accessibility for all as an integral part of the plan. The refurbishment or new developments should take into account the Internet of Things (IoT) paradigm shift in order to not only help PRM but also potentially any citizen because the two are inherently linked.

The universality and/or multi-functionality of accessibility maps should be recognised here. Such maps, including their relevant details such as barrier locations, can facilitate policy actions that lead towards an accessible for all public space. The removal of actual physical barriers should be a separate policy goal of the city and/or municipality. However, creating and sharing accessibility details and maps, communicating that information in an accessible manner, especially the accessibility characteristics of public spaces such as buildings, pavements, paths, and parks, facilitates the cooperative process of at least two PRM target groups. The first group are those people with reduced mobility issues and the second group consists of the people responsible for deciding and actually removing the physical barriers.

These ideas are in-line with the goals of the SISKOM Association, a Polish non-governmental organisation that is the originator and creator of the Warsaw Barrier Map.

Relevant improvements that would help make and disseminate more effective accessibility maps would have the following characteristic: present the locations and the accessibility characteristics of the point location, line and/or geographic area of the topographic objects as well as the relationships between them. This will contribute to (a) the recognition of the accessibility issues by providing effective documentation both on at medium to small scales, example at the city and district level of detail, (b) the recognition of the accessibility maps importance in the policy of accessible public spaces by addressing the added value it provides to the PRM community, and (c) reducing the transition phase from exclusive to inclusive urban space by facilitating the communication between all actors. 


\section{CONCLUSIONS AND FUTURE RESEARCH}

\subsection{Survey Conclusions}

Targeted information on disabled access should contain clear information about how accessible the venue is for PRM, including a description of the areas that are accessible and the relevant facilities available or any other provision made on the premises for disabled persons. Persons with motor disabilities need information on disabled access and openings such as ramped access and automatic doors, access within the premises such as wheelchair lifts, and facilities such as accessible toilets. The expected content of information on accessibility can also be defined by the aims of this information. Some examples of such aims include encouraging tourism, making travel choices with confidence when relevant information is provided because PRM can make the decision about visiting a particular destination. Other examples are the avoidance of paths that could be impassable, the facilitation of the journey preparation phase and assistance in active on-site tourism and navigation. The focus should be on sightseeing and enjoyment and not on searching for a route and/or changing one's destination because the path taken was impassible. Note this is only a short list to help one understand the potential requirements of PRM.

\subsection{Targeting Accessibility Information}

The following are conclusions related to improving the targeted information availability and comprehension with respect to the TG PRM:

1. The PRM need mobility information aids, in the form of a detailed description of the areas that are accessible and the relevant facilities available or any other provision made on the premises for disabled persons, at each of the following phases:

- The pre-visit phase when a decision must be made whether the site of interest offers the required accessibility services;

- Route, travel and sightseeing planning;

- 'Last mile' access or how the PRM will reach the final destination such as getting from the nearest car park or public transport stops, such as disabled car parking places and accessible paths to the site entrance;

- Active on-site tourism and navigation aids such as access to the ticket office, easy entrances and other door services, and dedicated on-site toilet access;

2. Accessibility Information is expected to be reliable, i.e. upto-date and complete;

3. The user must be able to perceive accessibility information and understand it. This means being aware of it and how to access the information as well as know what the information means and how to interact with it if necessary. The idea of an accessible format of accessibility information is based on the following: a) adjusted to physical abilities/disability types for example text messages for people with vision impairments, b) adjusted to cognition and/or comprehension abilities for example using simple language for instructions and, c) adjusted to a persons access to technology, abilities and competencies;
4. The visual form of the presented information can be provided as cartographic visualizations assuming some level of map reading /comprehension skills because the necessary information is spatial. Access to relevant information and geo-visualisations provided either by the authorities or through social media channels help in making travel significantly more accessible and successful to a wider variety of PRM in the TG.

\subsection{Discussion}

The main conclusion of the work presented here is the fact that there is still a lot of work not only to physically remove the barriers in the way of PRM to maximise autonomy but also that data barriers still exist in the form of access to barrier location and type details and the manner in which maps are produced, shared and displayed. The idea of Smart Cities providing automated updates to public works relevant to PRM as well as the sharing of information through Smart Citizens is certainly going to improve the data ingestion issue related to planning trips and the certainty related to the accuracy of those details. However, there is still the issue of producing the most readable and appropriate maps for the PRM depending on their level of mobility as well as cognitive ability. In this case, we believe that the technology is available today to break down those barriers through the ubiquitous access to smartphone technologies, wireless communication and social sharing platforms. These are all possible through the evolution of Smart Cities, access to smartphones and geovisualisation.

Our research will continue on this topic through the alternative design and implementation of accessibility map prototypes for the Wilanów palace and park complex as well as the Polish Army Museum in Warsaw based on our reviews. This more practical research will involve testing the map prototypes (both paper and digital forms) on a group of people with reduced mobility. The new accessibility map designs will also be made available to the institutions. It is expected that a document related to the work in producing the new accessibility maps including recommendations on how to make an effective accessibility map will be compiled. Ultimately, the goal is to get citizens, local government and ministerial projects involved to help maximise the accessibility of public spaces and a part of Smart City design.

\section{ACKNOWLEDGEMENTS}

J. Nowak Da Costa would like to acknowledge that this work was supported by a statutory grant from the Institute of Geodesy, Faculty of Civil Engineering and Geodesy of Military University of Technology, no. PBS/933/2016.

\section{REFERENCES}

Błedowski, P., Szatur-Jaworska, B., Szweda-Lewandowska, Z. and Kubicki, P., 2012. Raport na temat sytuacji osb starszych w polsce. Technical report.

Blichfeldt, B. S. and Nicolaisen, J., 2011. Disabled travel: Not easy, but doable. Current Issues In Tourism pp. 79-102.

Brodersen, L., 2001. Maps as communication: theory and methodology in cartography. Kortog Matrikelstyrelsen, Copenhagen, Denmark, p. 89.

Brodersen, L., 2009. Geo-communication and information design. Tankegang A/S, Denmark, p. 625. 
Brodersen, L., 2017. Geo-communication and information design. meta-carto-semiotics 1(1), pp. 1-13.

Darcy, S. and Dickson, T., 2009. A whole-of-life approach to tourism: The case for accessible tourism experiences. Journal of Hospitality and Tourism Management 16(1), pp. 32-44.

Dent, B., Torguson, J. and Hodler, T., 2009. Cartography: Thematic Map Design (6th Edition).

EC, 2015. Mapping and Performance check of the supply of Accessible Tourism services in Europe. Technical report, European Commision.

Eurostat, 2015. Eurostat regional yearbook 2015. eurostat statistical books. Online.

Farivar, C., 2018. Wazes crazy routing over a 32nuts. Ars Technica.

Ffrench, A., 2018. Disabled hit by 'poor planning' and lack of taxi rank at westgate shopping centre. Oxford Mail Online.

Field, K., 2018. Cartography. ESRI Press, p. 556.

Goodchild, M. F., 1992. Geographical data modeling. Computers \& Geosciences 18 , pp. 401-408.

Goodchild, M. F., 2007. Citizens as voluntary sensors: Spatial data infrastructure in the world of web 2.0. International Journal of Spatial Data Infrastructures Research 2, pp. 24-32.

Kaganek, K., Ambroży, T., Mucha, D., Jurczak, A., Bornikowska, A., Ostrowski, A., Janiszewska, R. and Mucha, T., 2017. Barriers to participation in tourism in the disabled. Polish Journal of Sport and Tourism.

Laura, A. G., 2017. Enat president's message: 12 june 2017. Online.

Mark, D. M., 1997. Cognitive perspectives on spatial and spatiotemporal reasoning. In: Geographic Information Research Bridging the Atlantic, London, Taylor \& Francis, pp. 308-319.

Müller, S., Kamieth, F., Braun, A.and Dutz, T. and Klein, P., 2013. User requirements for navigation assistance in public transit for elderly people. In: Proceedings of the 6th International Conference on Pervasive Technologies Related to Assistive Environments, Rhodes, Greece, pp. 27-30.

Nowak Da Costa, J., 2016. Towards building data semantic similarity analysis: Openstreetmap and the polish database of topographic objects. In: Baltic Geodetic Congress (Geomatics) Proceedings, Gdańsk, Poland, pp. 269-275.

Oliver, M., 2013. The social model of disability: thirty years on. Disability \& Society 28(7), pp. 10241026.

Organization, W. T., 2016a. Accessible tourism for all: An opportunity within our reach. Technical report, UNWTO, Madrid, Spain.

Organization, W. T., 2016b. Manual on Accessible Tourism for All: Principles, Tools and Best Practices Module I: Accessible Tourism Definition and Context. Technical report, UNWTO, Madrid, Spain.

Pimpa, W., Sarapirome, S. and Dasananda, S., 2014. Gis application to development of military cross-country movement maps at mae sot district, western thailand. Suranaree J. Sci. Technol. 21(3), pp. 215-232.

Pokonieczny, K., 2016. Methods of using self-organising maps for terrain classification, using an example of developing a military passability map. In: Dynamics in GIscience.
Slocum, T., McMaster, R., Kessler, F. and Howard, H., 2009. Thematic Cartography and Geovisualization, Third Edition. Pearson/Prentice Hall, Upper Saddle River, NJ, USA.

Space, B.-D. F. A. P. O., 2011. Manual in English. 2nd Edition, Berlin Senate Department for Urban Development. Website.

UNCRDP, 2006. United nations convention on the rights of persons with disabilities. Online.

Vaportzis, E., Clausen, M. G. and Gow, A. J., 2017. Older adults perceptions of technology and barriers to interacting with tablet computers: A focus group study. Frontiers in Psychology. 